\title{
Vascular Access
}

\section{Simone Cesaro and Federica Minniti}

\subsection{Introduction}

The central venous catheter (CVC) is a key tool for patients undergoing a HSCT, and its introduction in the oncology setting has represented a clear improvement in the quality of patient health care. The use of a CVC requires correct maintenance to prevent malfunctioning due to partial or complete occlusion, dislodgement, kinking, rupture, thrombosis, or life-threatening complications such as catheter-related bloodstream infections (CRBSI).

CVCs are being designated by:

- Duration (e.g., temporary or short-term versus permanent or long-term)

- Site of insertion (e.g., subclavian vein, femoral vein, jugular vein, basilic vein)

- Number of lumens (single, double, or triple lumen)

- Characteristic of tip (open tip or closed tip)

- Materials to reduce complications (e.g., impregnation with heparin, antibiotics, or silver)

S. Cesaro $(\square)$

Pediatric Hematology Oncology, Azienda

Ospedaliera Universitaria Integrata, Verona, Italy

e-mail: simone.cesaro@ aovr.veneto.it

F. Minniti

Mother and Child Department, Ospedale della Donna

e del Bambino, University of Verona, Verona, Italy
Table 22.1 shows the main maintenance actions for CVC (Cesaro et al. 2016).

Table 22.1 CVC maintenance: suggested main rules

1. Assessment of line functionality and dressing site daily for inpatients or every 2-3 days for outpatients

2. CVC care and maintenance as dictated by local policy or standard operating procedure ${ }^{\mathrm{a}}$

3. Vigorous mechanical scrub for manual disinfection prior to each CVC access and allow it to dry. Acceptable disinfecting agents include $70 \%$ isopropyl alcohol, iodophors (i.e., povidone-iodine), or $>0.5 \%$ chlorhexidine in alcohol solution

4. Change gauze dressing every 7 days or before in case of soiled, dampened, and loosened

5. Change the transfusion administration set and filter after the completion of each unit or every $4 \mathrm{~h}$. If more than 1 unit can be infused in $4 \mathrm{~h}$, the transfusion set can be used for a 4-h period

6. Change intermittent administration sets every $24 \mathrm{~h}$

7. Replace administration sets for parenteral nutrition solutions at least every $24 \mathrm{~h}$

8. Replace administration sets used for intravenous fat emulsions infused separately every $12 \mathrm{~h}$

9. Change caps every $72 \mathrm{~h}$ (or 7 days if pressurepositive device is used)

${ }^{a}$ There may be a variability among EBMT centers regarding the practice of CVC care and maintenance such as the use of sterile gloves and mask by provider/ assistant, the adoption of aseptic technique for all catheter entries, the use of prepackaged dressing change kit, the frequency of flushing, and the type of solution used for flushing $\mathrm{CVC}$ 


\subsection{Type of CVC Materials}

Catheter materials should be biocompatible, kink resistant, inherently chemically resistant and neutral, biostable, soft, and deformable and should have a high tensile strength (Lim et al. 2018; Frasca et al. 2010). The most commonly used materials are polyurethane, polyethylene and polytetrafluoroethylene (Teflon), polyvinylchloride (PVC), silicone, and Vialon (Borretta et al. 2018). Silicone catheters are flexible, chemically stable, and well tolerated. Polyurethane catheters are preferred to those made of polyethylene or PVC because of their lower rate of CRBSI and their lower friability (Frasca et al. 2010). Polytetrafluoroethylene catheters are rigid and lose X-ray transparency when injected with opaque solutions. Polyurethane has a superior tensile strength.

Non-tunneled, semirigid catheters are usually made of polyurethane, while tunneled catheters are usually made of both silicone and polyurethane (Lim et al. 2018). The superiority of polyurethane catheters compared with silicone is debated. The two catheter types have no difference in surface degradation; however, silicone catheters are more prone to material failure as a result of the development of surface irregularities due to loss of barium sulfate molecules and thrombotic occlusion. Conversely, polyurethane catheters have a higher susceptibility for catheterinduced venous thrombosis and CRBSI (BlancoGuzman 2018; Wildgruber et al. 2016).

\subsection{Type of CVC}

CVCs are classified in two main categories: tunneled and non-tunneled, according to whether or not they follow a subcutaneous route before accessing the central vein. Non-tunneled catheters are directly inserted into a peripheral or large central vein. Both tunneled and non-tunneled CVCs may have a single or multiple lumen. Tunnelization of CVCs was introduced to reduce the risk of infectious and mechanical (dislodgement) complications, and this type of CVC is ideal for long-term care (Cesaro et al. 2009).
Non-tunneled CVCs are usually inserted for a short to medium period (from 2-4 weeks to 1-3 months) (Lee and Ramaswamy 2018; Padmanabhan 2018). Tunneled CVCs are in turn classifiable in two subgroups: partially implanted and totally implanted. Partially implanted CVCs are characterized by an external part outside the patient's body whose extremity (hub) is used to draw blood sampling or to connect the infusion lines, a tunneled subcutaneous part with a Dacron cuff at a few centimeters from the skin entry point, and a final intravenous part with the tip positioned at the border between the superior vena cava and the right atrium (Padmanabhan 2018; Blanco-Guzman 2018). The Dacron cuff stimulates a fibrotic reaction of the subcutaneous tissues over 2-4 weeks ensuring stability and CVC securement. Both cuff and subcutaneous course are fundamental to prevent the CVC from becoming infected due to the migration of external microbes along the CVC. Broviac, Hickman, and Groshong CVCs belong to this group. Broviac-Hickman CVCs have an open tip and require the clamping of the external part of the CVC when they are not in use to avoid the backflow of the blood from the tip with breath or body movements. Groshong CVCs have a closed tip with lateral valves on their terminal part that open as fluid is withdrawn or infused, while they remain closed when the CVC is not in use. The CVC has to be clamped only if the catheter does not have a needle-free connector. The ideal situation to avoid backflow of blood is a neutral pressure needle-free connector with an open clamp (Padmanabhan 2018).

Totally implanted catheters (porth) consist of a reservoir (port) placed in a pocket in the subcutaneous tissue anteriorly on the chest wall, below the clavicle, that is connected to the catheter (Padmanabhan 2018; Blanco-Guzman 2018). This type of CVC has no part outside of the body, thus preserving the patient's body image and ensuring almost no limitations on sports activities, and body hygiene. The main drawback of this type of CVC is that its accessing needs a skin puncture with a special "noncoring" needle (Huber needle or gripper system). In case of frequently repeated port accesses, the 
procedure can be painful or discomforting for the patient, requiring the application of topical skin anesthetics for its prevention. Moreover, the needle does not permit the infusion or the extraction of high volumes making it less suitable for patients requiring high infusion or blood extraction rates. The recent introduction of port models with a modified reservoir chamber (vortex, tidal, power port) has allowed to obtain a higher flow rate suitable for leukapheresis, red blood cell exchange, extracorporeal photopheresis, and therapeutic plasma exchange (Blanco-Guzman 2018; Lim et al. 2018).

The peripherally inserted central catheter (PICC) is a CVC inserted into a vein of the arm, usually the basilic or cephalic veins; its tip is advanced through the axillary and subclavian veins up to the cavoatrial junction (Hashimoto et al. 2017; Cornillon et al. 2017). For more information on PICCs, see Chap. 32.

\subsection{Venous Access}

Central lines are usually inserted through the subclavian, the jugular, or, less frequently, the femoral vein. This last venous access is associated with a higher risk of infectious complications (O'Leary 2016), and it is more commonly used in critically ill patients admitted to intensive care units who require a non-tunneled CVC. Using the subclavian or jugular access, the tip of the catheter has to lie in the superior vena cava, just before the entrance of the right atrium, about 29-55 mm below the level of trachea carina (in adults). The incidence of pneumothorax after CVC insertion is about $1.5-3.1 \%$, and it is higher with subclavian vein catheterization, whereas the risk of hemorrhage and bruise is slightly more common with the jugular venous line access.

In the positioning of a PICC, the incannulation of the basilic vein is preferred to that of the cephalic vein as it has low risk of complications. To minimize the risk of complications due to venous catheterizations, the routine use of ultrasound guidance to cannulate the vein is recommended instead of the classical (blind) technique (Cornillon et al. 2017; Crocoli et al. 2015).
A chest X-ray must be performed at the end of the CVC insertion procedure to confirm that the line is positioned inside the superior vena cava and, for the cannulation of subclavian or jugular veins, no pneumothorax was inadvertently caused. Recently, the use of intracavitary ECG (electrocardiographic method) has also been approved for clinical use to evaluate the correct position of the catheter tip (Borretta et al. 2018).

\subsection{CVC Complications}

Catheter-related complications may be classified into infectious (local or systemic) and mechanical (occlusion, rupture, dislodgement, accidental self-removal, and thrombosis) (Cesaro et al. 2009). As the catheter is itself a risk for developing complications, when there is no further need for a catheter, it should be removed. Removal of the catheter must also be considered in the event of catheter dysfunction; CRBSI by Candida spp., Pseudomonas spp., Klebsiella spp., and Staphylococcus aureus; persistent bacteria colonization or recurrent CRBSI; or contraindications against anticoagulant therapy.

\subsubsection{Special Measures to Prevent Catheter-Related Infections}

The key rules to prevent infections are proper handwashing by the performing provider, the use of aseptic technique over the patient at insertion time, thorough cleaning of the insertion site, and periodic review of the CVC exit site (Cesaro et al. 2016). Impregnation of the CVC with heparin may reduce the incidence of infectious and thrombotic complications. To prevent CRBSI and tunnel or exit-site infection, medicationimpregnated dressings with different antimicrobial materials were developed to decrease the production of the biofilm by microorganisms and decrease the adhesion of them to the catheter walls. The most commonly used impregnating medications are chlorhexidine gluconate, silver sulfadiazine, rifampin, and minocycline (Frasca et al. 2010). Chlorhexidine gluconate impreg- 
nates the whole dressing or is applied using an impregnated sponge (e.g., Biopatch ${ }^{\circledR}$ ) and covered by a transparent polyurethane semipermeable transparent dressing (Ullman 2015).

\subsection{Catheters for Leukapheresis}

The procedure of stem cell collection by apheresis is performed both for auto- and allo-HSCT to obtain PBSC (O'Leary 2016). As the procedure requires sustained high blood flow rates (50$100 \mathrm{~mL} / \mathrm{min}$ ), an adequate venous access is needed (O'Leary 2016). Peripheral access placed in the basilic, cephalic, brachial, median cubital and radial veins is recommended (Padmanabhan 2018; Lim et al. 2018; Hölig et al. 2012). Considering that the placement of a central CVC is associated with potentially life-threatening complications such as pneumothorax, bleeding, and embolism (Hölig et al. 2012), its use is not recommended for PBSC collection of a healthy volunteer donor. Conversely, in the case of autoPBSC, if the patient has no adequate peripheral or central venous access, a temporary nontunneled CVC may be placed in the internal jugular, subclavian, or femoral veins (Padmanabhan 2018; Lim et al. 2018; Vacca et al. 2014; Hölig et al. 2012; Cooling 2017a). Catheter removal is performed on donor laboratory values (PLT $>50 \times 10^{9} / \mathrm{L}$ ) or after the assessment of an adequate CD34+ dose and successful cryopreservation of the HPC product (O'Leary 2016; Vacca et al. 2014).

Partially implanted silicone CVCs are often used by pediatric oncologists-hematologists because they are most suitable for long-term complex treatment (Wildgruber et al. 2016). In the case of leukapheresis procedure, silicone CVCs are not ideal because they are more prone to collapse during automatic apheresis (Ridyard et al. 2017). On the other hand, the harvesting procedure of PBSC, which requires high blood flow rates and a large needle, may be difficult in children below $10 \mathrm{~kg}$ using a temporary peripheral venous access due to the small size of veins (Padmanabhan 2018; Cesaro et al. 2016). In this case, the placement of a short-term CVC made of polyurethane may be needed (Cooling 2017a, b). However, in younger children, the rigidity of such material and the narrower lumens of the veins may represent a potential risk for thrombosis and infection (Ridyard et al. 2017; Cooling 2017b; Vacca et al. 2014).

\section{Key Points}

\begin{tabular}{|c|c|c|}
\hline \multicolumn{3}{|c|}{ CVC indications and insertion } \\
\hline \multirow[t]{4}{*}{$\begin{array}{l}\text { 1. Type of } \\
\text { CVC }\end{array}$} & \multirow{2}{*}{$\begin{array}{l}\text { Tunneled } \\
\text { CVCs/Port/ } \\
\text { PICCs }\end{array}$} & $\begin{array}{l}\text { Long-term therapy } \\
\text { (months, years) }\end{array}$ \\
\hline & & $\begin{array}{l}\text { Port for intermittent } \\
\text { use, tunneled CVC } \\
\text { for continuous use } \\
\text { Suitable for } \\
\text { inpatient and } \\
\text { outpatient }\end{array}$ \\
\hline & \multirow[t]{2}{*}{$\begin{array}{l}\text { Non-tunneled } \\
\text { CVCs }\end{array}$} & $\begin{array}{l}\text { Short-term therapy } \\
\text { (2-4 weeks, } \\
1-3 \text { months) }\end{array}$ \\
\hline & & $\begin{array}{l}\text { Suitable for } \\
\text { inpatient }\end{array}$ \\
\hline $\begin{array}{l}\text { 2. Number } \\
\text { of lumens }\end{array}$ & $\begin{array}{l}\text { Single lumen } \\
\text { vs Double } \\
\text { lumen }\end{array}$ & $\begin{array}{l}\text { Double lumen in } \\
\text { patients undergoing } \\
\text { HSCT, critically ill } \\
\text { patients, intensive } \\
\text { intravenous therapy }\end{array}$ \\
\hline \multirow[t]{4}{*}{ 3. Insertion } & \multirow{2}{*}{$\begin{array}{l}\text { Percutaneous/ } \\
\text { minimally } \\
\text { invasive }\end{array}$} & $\begin{array}{l}\text { Ultrasound guidance } \\
\text { recommended }\end{array}$ \\
\hline & & $\begin{array}{l}\text { Adequate training } \\
\text { required }\end{array}$ \\
\hline & $\begin{array}{l}\text { Cutdown } \\
\text { approach }\end{array}$ & $\begin{array}{l}\text { Very limited } \\
\text { indication } \\
\text { (premature infants) }\end{array}$ \\
\hline & & $\begin{array}{l}\text { Experienced } \\
\text { operator }\end{array}$ \\
\hline \multirow[t]{2}{*}{ 4. Material } & Silicone & Tunneled CVC \\
\hline & Polyurethane & $\begin{array}{l}\text { Tunneled and } \\
\text { non-tunneled CVC }\end{array}$ \\
\hline
\end{tabular}

\section{References}

Blanco-Guzman MO. Implanted vascular access device options: a focus review on safety and outcomes. Transfusion. 2018;58:558-68.

Borretta L, MacDonald T, Digout C, et al. Peripherally inserted central catheters in pediatric oncology patients: a 15-year population-based review from Maritimes, Canada. J Pediatr Hematol Oncol. 2018;40:e55-60. 
Cesaro S, Cavaliere M, Pegoraro A, et al. A comprehensive approach to the prevention of central venous catheter complications: results of 10-year prospective surveillance in pediatric hematology-oncology patients. Ann Hematol. 2016;95:817-25.

Cesaro S, Tridello G, Cavaliere M, et al. Prospective, randomized trial of two different modalities of flushing central venous catheters in pediatric patients with cancer. J Clin Oncol. 2009;27:2059-65.

Cooling L. Performance and safety of femoral central venous catheters in pediatric autologous peripheral blood stem cell collection. J Clin Apher. 2017a;32:501-16.

Cooling L. Procedure-related complications and adverse events associated with pediatric autologous peripheral blood stem cell collection. J Clin Apher. 2017b;32:35-48.

Cornillon J, Martignoles JA, Tavernier-Tardy E, et al. Prospective evaluation of systematic use of peripherally inserted central catheters (PICC lines) for the home care after allogenic hematopoietic stem cells transplantation. Support Care Cancer. 2017;25:2843-7.

Crocoli A, Tornesello A, Pittiruti M,. et al. Central venous access devices in pediatric malignancies: a position paper of Italian Association of Pediatric Hematology and Oncology. J Vasc Access. 2015;16(2):130-6.

Frasca D, Dahyot-Fizelier C, Mimoz O. Prevention of central venous catheter-related infection in the intensive care unit. Crit Care. 2010;14:212.

Hashimoto Y, Fukuta T, Maruyama J, et al. Experience of peripherally inserted central venous catheter in patients with hematologic disease. Intern Med. 2017;56:389-93.
Hölig K, Blechschmidt M, Kramer M, et al. Peripheral blood stem cell collection in allogeneic donors: impact of venous access. Transfusion. 2012;52(12): 2600-5.

Lee K, Ramaswamy RS. Intravascular access devices from an interventional radiology perspective: indications, implantation techniques, and optimizing patency. Transfusion. 2018;58(Suppl 1):549-57.

Lim HS, Kim SM, Kang DW. Implantable vascular access devices-past, present and future. Transfusion. 2018;58:545-8.

O'Leary MF. Venous access for hematopoietic progenitor cell collection: an international survey by the ASFA HPC donor subcommittee. J Clin Apher. 2016;31(6):529-34.

Padmanabhan A. Cellular collection by apheresis. Transfusion. 2018;58:598-604.

Ridyard $\mathrm{CH}$, Plumpton $\mathrm{CO}$, Gilbert RE, Hughes DA. Cost-effectiveness of pediatric central venous catheters in the UK: a secondary publication from the CATCH clinical trial. Front Pharmacol. 2017;8:644.

Ullman AJ, Cooke ML, Mitchell M, et al., Dressings and securement devices for central venous catheters (CVC). Cochrane Database Syst Rev. 2015;(9):CD010367.

Vacca M, Perseghin P, Accorsi P, et al. Central venous catheter insertion in peripheral blood hematopoietic stem cell sibling donors: the SIdEM (Italian Society of Hemapheresis and Cell Manipulation) point of view. Transfus Apher Sci. 2014;50:200-6.

Wildgruber M, Lueg C, Borgmeyer S, et al. Polyurethane versus silicone catheters for central venous port devices implanted at the forearm. Eur $\mathrm{J}$ Cancer. 2016;59:113-24.

Open Access This chapter is licensed under the terms of the Creative Commons Attribution 4.0 International License (http://creativecommons.org/licenses/by/4.0/), which permits use, sharing, adaptation, distribution and reproduction in any medium or format, as long as you give appropriate credit to the original author(s) and the source, provide a link to the Creative Commons license and indicate if changes were made.

The images or other third party material in this chapter are included in the chapter's Creative Commons license, unless indicated otherwise in a credit line to the material. If material is not included in the chapter's Creative Commons license and your intended use is not permitted by statutory regulation or exceeds the permitted use, you will need to obtain permission directly from the copyright holder.

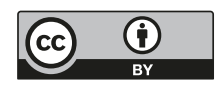

